This is the last draft sent to the Editorial by the authors of the article:

M. GÓMEZ, S. F. MEDINA, A. QUISPE
"Evolution of austenite microstructure and precipitation state during hot
rolling of a Nb-microalloyed steel"
Materials Science Forum
Vol. 426-432 (2003), Pages: $1535-1540$
DOI: $10.4028 /$ www.scientific.net/MSF.426-432.1535
ISSN: $0255-5476$

To be published in Digital.CSIC, the Institutional Repository of the Spanish National Research Council (CSIC)

See more papers from the authors on:

$\underline{\text { http://digital.csic.es }}$

http://www.researcherid.com/rid/B-7922-2008 


\title{
Evolution of austenite microstructure and precipitation state during hot rolling of a Nb-microalloyed steel
}

\author{
M. Gómez ${ }^{1}$, S. F. Medina ${ }^{1}$ and A. Quispe ${ }^{2}$ \\ ${ }^{1}$ National Centre for Metallurgical Research (CENIM). Av. Gregorio del Amo, 28040 Madrid Spain. \\ ${ }^{2}$ National University "Jorge Basadre", Av Miraflores s/n, University City, Tacna (Perú). \\ (mgomez@cenim.csic.es; smedina@cenim.csic.es; abqc@unjbg.edu.pe.)
}

Keywords: microalloyed steel, hot rolling simulation, recrystallization, precipitation, transmission electron microscopy

\begin{abstract}
Hot torsion tests were used to simulate hot rolling of a Nb-microalloyed steel. Subsequent graphic representation of Mean Flow Stress (MFS) versus the inverse of absolute temperature for each pass allowed to know the critical rolling temperatures $\left(T_{n r}, A_{r 3}, A_{r 1}\right)$ and residual stress accumulated in austenite just before austenite to ferrite phase transformation. It has been found that, as successive rolling passes are applied at temperatures below $T_{n}$, mean precipitate size decreases as a result of deformation applied and hardening by incomplete recrystallization of austenite.
\end{abstract}

\section{Introduction}

Most hot rolled microalloyed steels contain Niobium, since this element presents the advantage over vanadium of being less soluble in austenite at the temperatures usual in rolling. This low solubility leads to greater hardening of the austenite in the final stage of rolling, which ultimately implies a refining of the final ferrite/pearlite microstructure and consequently a generalized improvement of mechanical properties, especially toughness.

No-recrystallization temperature $\left(\mathrm{T}_{\mathrm{nr}}\right)$ represents the start of the inhibition of static recrystallization of austenite during hot rolling. The most common method for determining $\mathrm{T}_{\mathrm{nr}}$ consists of simulating successive rolling passes and then graphically representing the mean flow stress (MFS) versus the inverse of the absolute temperature for each of the simulated passes. The inhibition of recrystallization indicated by $\mathrm{T}_{\mathrm{nr}}$ appears as a rise in the slope of the MFS curve and in steel studied is mainly caused by strain-induced precipitation of niobium carbonitrides.

This method also offers the possibility of obtaining the $A_{r 1}$ and $A_{r 3}$ phase transformation temperatures when the austenite is being deformed in conditions similar to rolling $[1,2]$ as well as the residual stress accumulated in the austenite instants before the $\gamma \rightarrow \alpha$ transformation [3].

In order to observe the microstructural changes and study the strain induced precipitation state during hot rolling, several samples were quenched from different temperatures along a hot rolling simulation schedule.

\section{Experimental procedure}

The steel studied, whose composition is shown in Table 1, was manufactured by Electroslag Remelting (ESR).

Rolling simulations tests were carried out in a computer-controlled hot torsion machine, on specimens with a gauge length of $50 \mathrm{~mm}$ and a diameter of $6 \mathrm{~mm}$. Prior to the simulation tests the specimens were austenitized at a temperature of $1250^{\circ} \mathrm{C}$ for $10 \mathrm{~min}$. This reheating conditions were enough to dissolve completely the Niobium precipitates, as solubility temperatures calculated for carbonitrides, nitrides and carbides were equal to $1145{ }^{\circ} \mathrm{C}, 1112{ }^{\circ} \mathrm{C}$ and $1103{ }^{\circ} \mathrm{C}$, respectively [4]. The temperature was then lowered to that corresponding to the first pass, which was $1150^{\circ} \mathrm{C}$. The simulation consisted of the performance of 20 passes, with a temperature step of $25^{\circ} \mathrm{C}$ between 
passes and an interpass time of $100 \mathrm{~s}$, the last pass being carried out at $675^{\circ} \mathrm{C}$. The strain applied in each pass was of 0.20 and the strain rate was equal to $3.63 \mathrm{~s}^{-1}$.

To study the microstructure and precipitation state during rolling, four samples were water quenched from different temperatures along rolling schedule. In every sample a last deformation step was performed and then temperature was lowered $25{ }^{\circ} \mathrm{C}$ for an interpass time of $100 \mathrm{~s}$ to reach the quench temperature. Microstructures were observed on a longitudinal surface and the characteristics of the precipitates were determined by TEM, using the carbon extraction replica technique.

Table 1. Chemical composition of steel studied [mass \%].

\begin{tabular}{|c|c|c|c|c|c|c|c|c|c|c|}
\hline $\mathrm{C}$ & $\mathrm{Si}$ & $\mathrm{Mn}$ & $\mathrm{P}$ & $\mathrm{S}$ & $\mathrm{Al}$ & $\mathrm{Cu}$ & $\mathrm{Cr}$ & $\mathrm{Nb}$ & $\mathrm{N}$ & $\mathrm{O}$ \\
\hline 0.094 & 0.27 & 1.35 & 0.025 & 0.009 & 0.003 & 0.014 & 0.072 & 0.040 & 0.0072 & 0.0044 \\
\hline
\end{tabular}

\section{Results and Discussion}

Hot rolling simulation. The torsion test gives the values of torque applied versus the number of turns made on the specimen, which are transformed respectively into equivalent stress and strain using Von Mises criterion.[5]

Fig. 1 shows the simulation of 20 rolling passes for the steel studied. At first deformations, stress raises as temperature decreases, after which there is a change in the slope with a growth in the stress, which means a greater tendency to strengthening. Later, stress drops and grows again at final passes. The meaning of these zones is better explained by observing Fig. 2 which shows the graphic representation of mean flow stress (MFS) versus the inverse of the absolute temperature. MFS is determined in each step by dividing the area below the stress-strain curve by the strain applied.

In Fig. 2 it is possible to see four different zones. In the first zone (I), which corresponds to deformations at high temperatures, MFS grows as the temperature decreases. Austenite recrystallizes completely between passes and there is no accumulated stress. The increase in stress is due only to the decrease in temperature. In the second zone of the curve (II) there is a change in the slope, which indicates a greater tendency towards hardening. Here the stress accumulates in the austenite, whose recrystallization between passes is partially inhibited. The third phase (III), characterized by a drop in MFS as the temperature decreases, corresponds to the austenite $\rightarrow$ ferrite partial transformation. In the fourth and final region (IV), where the stress again rises as the temperature drops, the austenite $\rightarrow$ ferrite transformation finishes and the eutectoid transformation takes place.

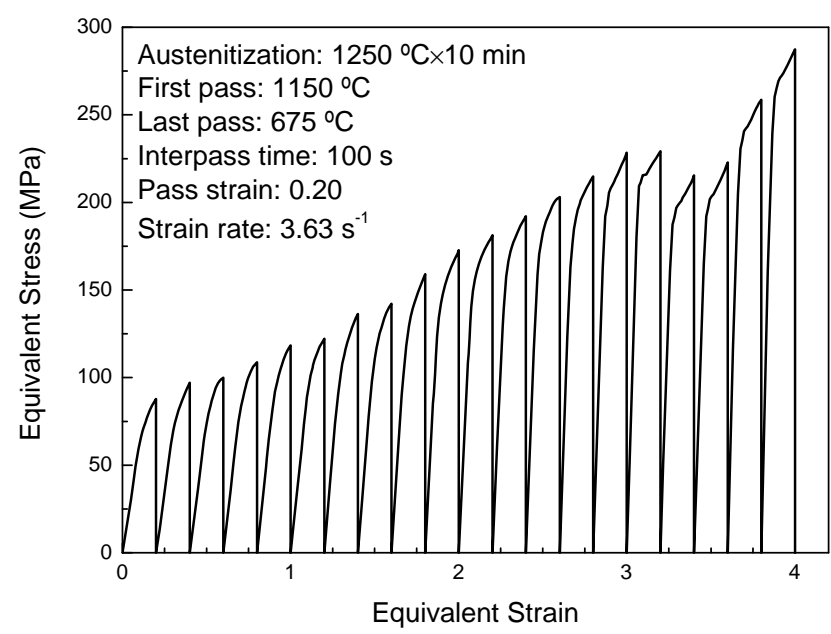

Fig. 1. Stress-strain curves corresponding to 20 pass torsion sequence. 


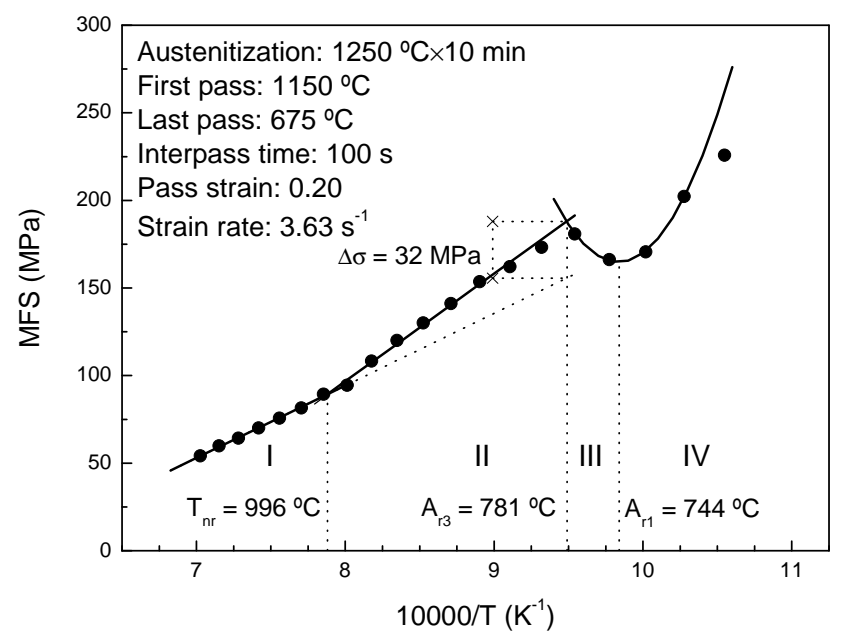

Fig. 2. Dependence of Mean Flow Stress (MFS) on inverse of absolute temperature, according to given schedule. Determination of critical temperatures and accumulated stress $(\Delta \sigma)$.

The intersection of the straight regression lines of phases I and II defines the value of $\mathrm{T}_{\mathrm{nr}}$, and the intersection of the regression lines of phases II and III determines the value of $A_{r 3}$. The value of $A_{r 1}$ is placed at a point close to the minimum of the parabola corresponding to phases III and IV [2]. Temperature $\mathrm{A}_{\mathrm{r} 3}$ has been reached with a deformed austenite phase and thus with an accumulated residual stress $\Delta \sigma$. The value of $\Delta \sigma$ can be measured from the graph of MFS versus the inverse of the temperature and will be given by the length of the vertical segment drawn at $\mathrm{A}_{\mathrm{r} 3}$ and limited by the phase I regression line and the intersection with the phase II straight line, as is illustrated in Fig. 2. In this way, the values found for the three critical temperatures and accumulated stress were: $\mathrm{T}_{\mathrm{nr}}$ $=996{ }^{\circ} \mathrm{C}, \mathrm{A}_{\mathrm{r} 3}=781^{\circ} \mathrm{C}, \mathrm{A}_{\mathrm{r} 1}=744^{\circ} \mathrm{C}, \Delta \sigma=32 \mathrm{MPa}$.

Quenched samples. Fig. 3a shows that austenite deformed at temperatures above $\mathrm{T}_{\mathrm{nr}}$ reaches complete recrystallization between passes, and presents a microstructure of equiaxed grains. For lower temperatures, austenite only recrystallizes partially during interpass time and grains are more elongated as temperature is decreased. Although this is not easily visible in Fig. 3b where temperature is near $\mathrm{T}_{\mathrm{nr}}$, this hardened structure can be observed in Figs. 3c and 3d, corresponding to temperatures well below $\mathrm{T}_{\mathrm{nr}}$. However, deformation conditions (pass strain, interpass time) were not enough to produce pancaking at the end of hot rolling simulation.

Strain accumulation in austenite from $\mathrm{T}_{\mathrm{nr}}$-manifested in the increase in accumulated stress measured on MFS curve, and elongation of grains observed in micrographs- is mainly caused by inhibition of static recrystallization originated by pinning effect of very fine $\mathrm{Nb}$ precipitates on austenite grain boundary motion. Precipitation state was studied by TEM (Fig. 4) for three of the quenched samples and it was found that as successive rolling passes are applied and temperature is lowered, mean precipitate size decreases (Table 2). When steel is deformed, applied stress provokes an increase in dislocation density ( $\rho)$ from Eq. 1 [6,7]:

$$
\rho=\left(\frac{\sigma-\sigma_{y}}{M \alpha \mu b}\right)^{2} .
$$

where $\sigma$ and $\sigma_{\mathrm{y}}$ are respectively the flow stress and yield stress at the deformation temperature, $M$ is Taylor factor (3.1 for f.c.c. crystals), $\alpha$ is a constant equal to $0.15, \mu$ is shear modulus and $b$ the Burgers vector. In the three-dimensional network of dislocations, the density of dislocation nodes $N_{v}$, which can be equated to the density of heterogeneous nucleation sites, is given as:

$$
N_{v}=0.5 \rho^{3 / 2} .
$$




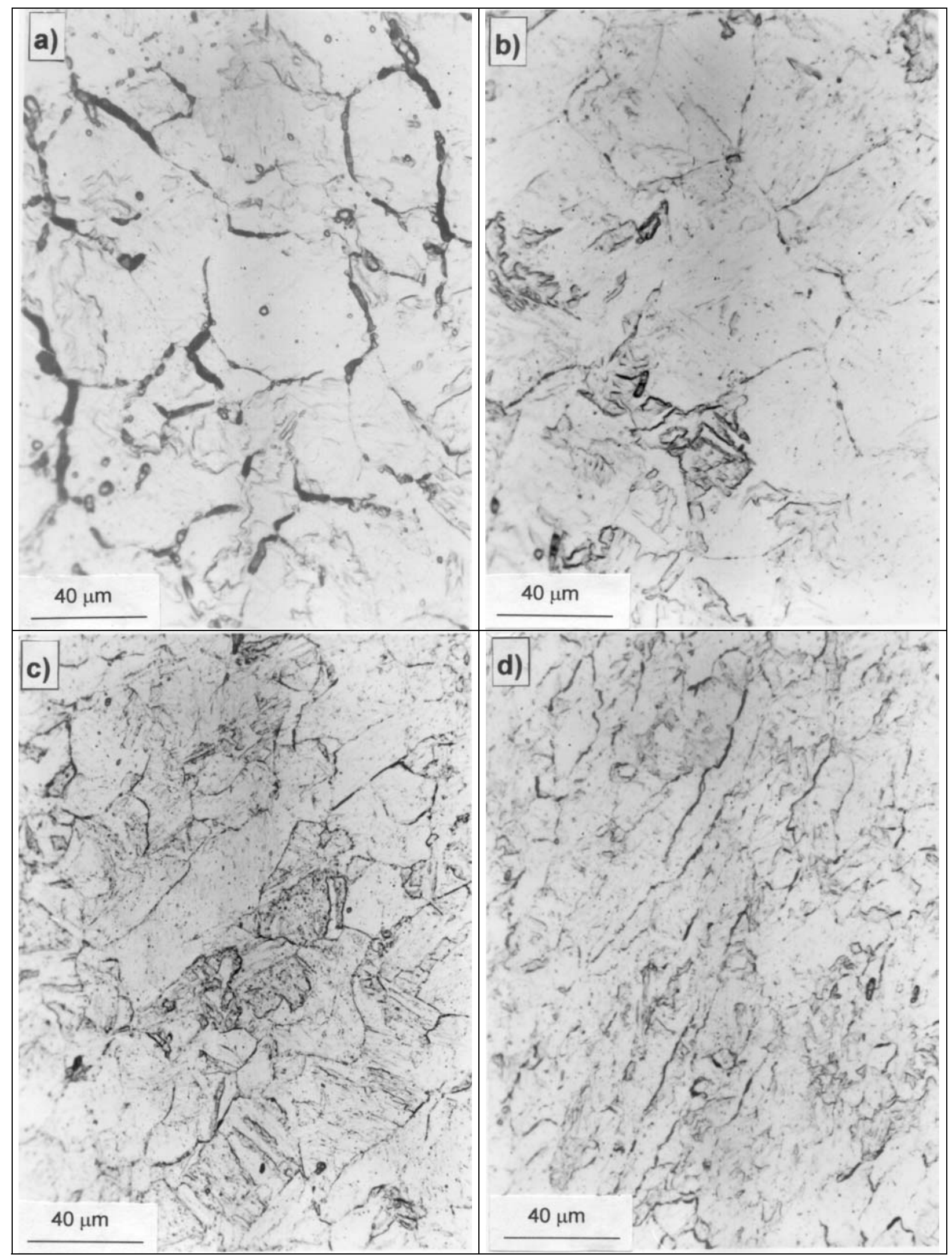

Fig. 3. Microstructures obtained by simulations of following conditions: pass strain 0.20 , pass strain rate $3.63 \mathrm{~s}^{-1}$, interpass time $100 \mathrm{~s}$. a) Final pass temperature $1050{ }^{\circ} \mathrm{C}$, quench at $1025{ }^{\circ} \mathrm{C}$; b) Final pass temperature $975{ }^{\circ} \mathrm{C}$, quench at $950{ }^{\circ} \mathrm{C}$; c) Final pass temperature $900{ }^{\circ} \mathrm{C}$, quench at $875{ }^{\circ} \mathrm{C}$; d) Final pass temperature $850{ }^{\circ} \mathrm{C}$, quench at $825^{\circ} \mathrm{C}$. 


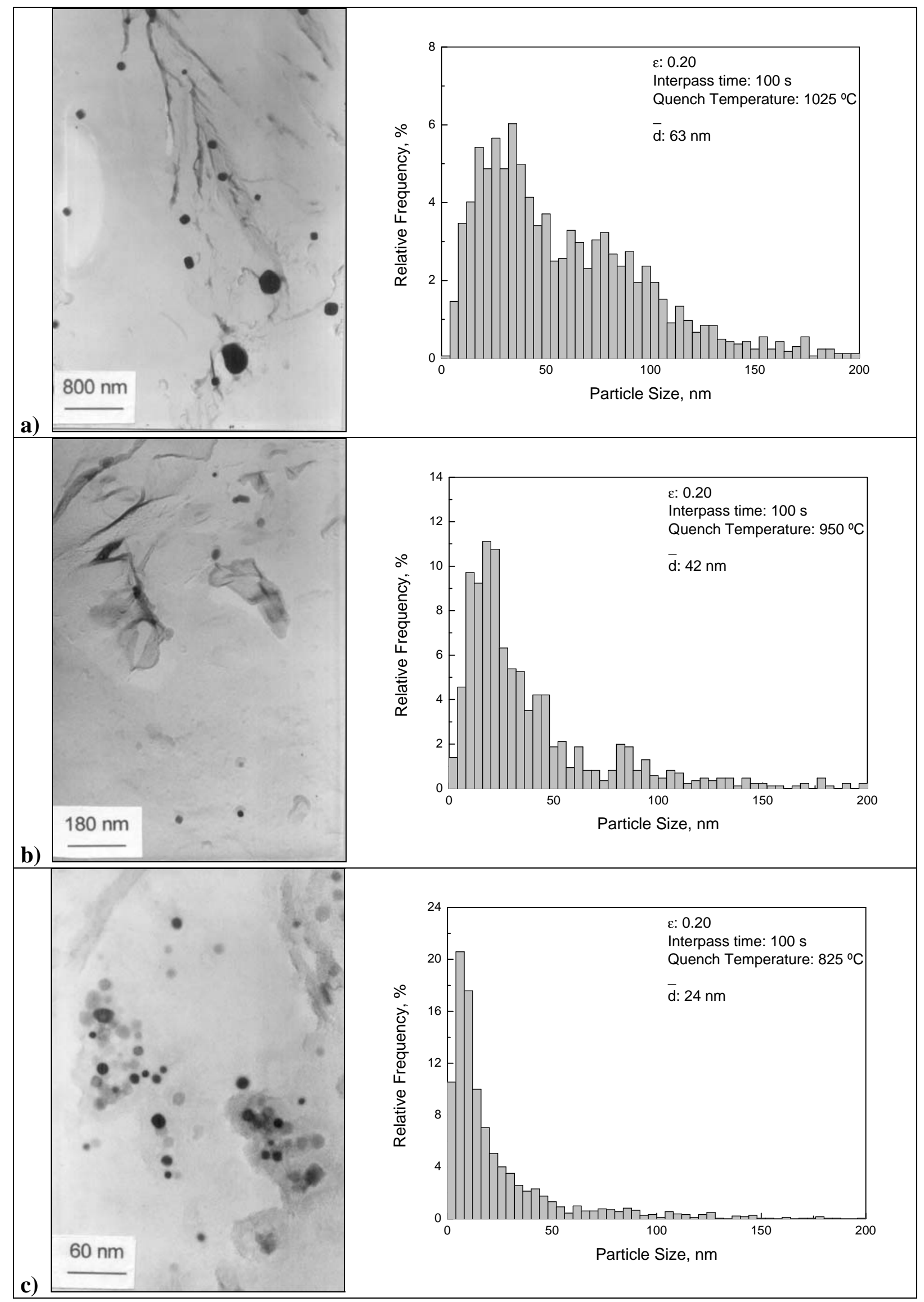

Fig. 4. TEM images showing $\mathrm{Nb}$ precipitates and corresponding precipitate size distributions. a) Quench at $1025^{\circ} \mathrm{C}$; b) Quench at $950^{\circ} \mathrm{C}$; c) Quench at $825^{\circ} \mathrm{C}$.

Table 2. Mean Precipitate size for different final rolling pass temperatures [nm]. 


\begin{tabular}{|c|c|c|c|c|}
\hline Strain & Strain rate $\left[\mathrm{s}^{-1}\right]$ & Interpass time [s] & Quench Temperature $\left[{ }^{\circ} \mathrm{C}\right]$ & Mean precipitate size [nm] \\
\hline 0.20 & 3.63 & 100 & 1025 & 63 \\
\hline 0.20 & 3.63 & 100 & 950 & 42 \\
\hline 0.20 & 3.63 & 100 & 825 & 24 \\
\hline
\end{tabular}

Hence, the rise in stress $\left(\sigma-\sigma_{y}\right)$ during deformation leads to an increase in the number of available sites for the nucleation of precipitates. The stress will be particularly increased if steel is being deformed at $\mathrm{T}<\mathrm{T}_{\mathrm{nr}}$, where partially recrystallized austenite accumulates a supplementary stress apart from that merely caused by temperature diminution. Consequently, nucleation rate of precipitates will augment, leading to a very high precipitate number density even in the early stages of interpass time after deformation. Traditional theories of coarsening by Ostwald ripening $[8,9]$ affirm that precipitate coarsening will not start before the finish of nucleation and growth stages (i.e. curve "C" of precipitation finish has been reached). Other authors [6,7], have shown that coarsening begins at a very early stage of precipitation and leads to a significant decrease in precipitate number density. During time after deformation, coarsening of precipitates (greatly favoured by accelerated solute diffusion through the dislocation network or pipe diffusion) can occur simultaneously with growth. In any case, even though precipitates quickly entered the growth and coarsening regime, the very high nucleation rate will lead to a smaller precipitate radius.[6]

If after interpass time and temperature diminution a further deformation is given, incomplete recrystallization of austenite due to small size of particles will lead again to stress accumulation. During subsequent interpass time, new particles will nucleate and grow in new dislocation nodes created by the aforementioned process (Eqs. 1, 2). Additionally the original dislocation network will be displaced by the deformation applied and the pre-existing particles will not be connected by dislocations so the coarsening by accelerated pipe diffusion can no longer occur in those particles, which during interpass time will grow slowly by volume diffusion [7]. In this manner, progressive increase in hardening and diminution of precipitate size can be explained as a coupled phenomenon.

\section{Acknowledgements}

The authors would like to thank I3P Program (CSIC/European Social Fund) for funding the grant of Eng. M. Gómez and Secr. de Estado de Educacion y Universidades for the stay of Dr. Quispe.

\section{References}

[1] A. Najafi-Zadeh, S. Yue and J.J. Jonas: ISIJ Int., Vol. 32 (1992), p. 213.

[2] F.H. Samuel, S. Yue, J.J. Jonas and B.A. Zbinden: ISIJ Int. Vol. 29, (1989), p. 878.

[3] S.F. Medina, M.I. Vega and M. Chapa: Mater. Sci. Technol. Vol. 16, (2000), p. 163.

[4] E.T. Turkdogan: Iron Steelmaker Vol. 16 (1989), p. 61.

[5] A. Faessel: Rev. Métall. Cah. Inf. Tech. Vol. 33, (1976), p. 875.

[6] B. Dutta, E. J. Palmiere and C. M. Sellars. Acta Mater. Vol 49 (2001), p. 785.

[7] B. Dutta, E. Valdes and C. M. Sellars. Acta Metall. Mater. Vol 40 (1992), p. 653

[8] I. M. Lifshitz and V. V. Slyosov. J. Phys. Chem. Solids Vol. 19 (1961), p. 35

[9] C. Wagner. Z. Electrochem Vol. 65 (1961), p. 581. 